\title{
BMJ Open The relationship between red blood cell distribution width and blood pressure abnormal dipping in patients with essential hypertension: a cross-sectional study
}

\author{
Dan Su, ${ }^{1}$ Qi Guo, ${ }^{1}$ Ya Gao, ${ }^{2}$ Jin Han, ${ }^{3}$ Bin Yan, ${ }^{2}$ Liyuan Peng, ${ }^{2}$ Anqi Song, ${ }^{1}$ \\ Fuling Zhou, ${ }^{4}$ Gang Wang ${ }^{2}$
}

To cite: Su D, Guo Q, Gao Y, et al. The relationship between red blood cell distribution width and blood pressure abnormal dipping in patients with essential hypertension: a crosssectional study. BMJ Open 2016:6:e010456.

doi:10.1136/bmjopen-2015010456

- Prepublication history for this paper is available online. To view these files please visit the journal online (http://dx.doi.org/10.1136/ bmjopen-2015-010456).

Received 4 November 2015 Revised 25 January 2016 Accepted 29 January 2016

CrossMark

For numbered affiliations see end of article.

Correspondence to Professor Gang Wang; gang_wang@mail.xjtu.edu.cn

\section{ABSTRACT}

Objective: To investigate whether red blood cell distribution width (RDW) is associated with the blood pressure (BP) reverse-dipper pattern in patients with hypertension.

Design: Cross-sectional study.

Setting: Single centre.

Participants: Patients with essential hypertension were included in our study $(\mathrm{n}=708)$. The exclusion criteria included age $<18$ or $>90$ years, incomplete clinical data, night workers, diagnosis of secondary hypertension, under antihypertensive treatment, intolerance for the $24 \mathrm{~h}$ ambulatory BP monitoring (ABPM) and BP reading success rate $<70 \%$.

Measurement: Physical examination and ABPM were performed for all patients in our study. The value of RDW was measured using an automated haematology analyser.

Statistical methods: The distribution of RDW in patients with hypertension among different circadian BP pattern groups was analyzed using analysis of variance (ANOVA). Multinomial logistic regression was applied to explore the associations of RDW and other relevant variables with $A B P M$ results.

Results: There was significantly increased RDW in reverse dippers $(13.52 \pm 1.05)$ than dippers $(13.25 \pm 0.85)$ of hypertension $(p=0.012)$. Moreover, multinomial logistic regression analysis showed that RDW (OR $1.325,95 \% \mathrm{Cl} 1.037$ to $1.692, \mathrm{p}=0.024)$ and diabetes mellitus (OR 2.286, $95 \% \mathrm{Cl} 1.380$ to $3.788, \mathrm{p}=0.001$ ) were significantly different when comparing the reversedipper BP pattern with the dipper pattern. However, there was no difference of RDW between the non-dipper pattern and the reverse-dipper pattern (OR 1.036, 95\% Cl 0.867 to $1.238, p=0.693$ ). In addition to this, RDW was negatively correlated with the decline rate of nocturnal systolic BP $(r=-0.113 ; p=0.003)$ and diastolic $B P(r=-0.101 ; p=0.007)$.

Conclusions: Our results suggested that RDW might associate with the abnormal dipper BP patterns of either reverse dipping or non-dipping homogeneously examined with $24 \mathrm{~h}$ ABPM.
Strengths and limitations of this study

- This is the first study to evaluate red blood cell distribution width (RDW) levels in the reversedipper pattern of blood pressure (BP).

- RDW is found to be associated with abnormal dipper BP patterns of either reverse dipping or non-dipping homogeneously.

- Our study had a cross-sectional design, whereas a longer period of prospective observation may provide more prognostic information.

- The participants in our study are exclusively limited to northern Chinese patients from a single centre.

- Specific markers of oxidative stress and inflammation were not investigated to reveal the exact mechanism of this association.

\section{INTRODUCTION}

Blood pressure (BP), as one of the vital signs, presents strong diagnostic and prognostic values, especially in hypotension and hypertension. ${ }^{1}$ However, BP variations among different situations, activities and medical conditions are regulated by the nervous and endocrine systems. Resting BPs never represents the whole profile of circulation dynamics. Ambulatory BP monitoring (ABPM), which offers us the average BP, variability and circadian dipping status across a $24 \mathrm{~h}$ period, is considered the gold standard for diagnosis and the best predictor of the future end organ damage in patients with chronic hypertension. ${ }^{2-4}$ The common circadian variation of $\mathrm{BP}$ presents a morning increase, a small postprandial decline and a $>10 \%$ decrease in systolic BP (SBP) during sleep compared with daytime $\mathrm{BP}$, and this is known as BP dipping. ${ }^{5}$ Conversely, reversedipper hypertension, which was regarded as 
a variant of non-dipper, defined as an increase in SBP at night, was found to be predictor of cardiovascular events in patients with hypertension. ${ }^{6-8}$

Red blood cells (RBCs), formally known as erythrocytes, are one of the most important blood cells. RBCs deliver oxygen to the whole body via the circulatory system. The RBC distribution width (RDW), which is routinely detected in blood samples and widely used in hospital, describes the variation in RBC size. ${ }^{9}{ }^{10} \mathrm{RDW}$ is usually elevated in conditions of increased erythrocyte destruction or ineffective erythropoiesis. ${ }^{11}$ Clinical and experimental researches suggest that the assessment of RDW should be broadened far beyond the diagnostic value for anaemia and it may serve as an important biomarker in a variety of acute and chronic pathological conditions. ${ }^{12}{ }^{13}$ In recent years, RDW has been demonstrated to be independently associated with morbidity and mortality in cardiovascular and other various diseases, including coronary artery disease, heart failure, diabetes, stroke and venous thromboembolism. ${ }^{14-17}$ It is reported that RDW is elevated in patients with hypertension compared with those with normotension. ${ }^{18}$ Additionally, studies have revealed that RDW levels are significantly higher in patients with hypertension with a non-dipper pattern compared with those with a dipper pattern. ${ }^{18} 19$ However, it should be noticed that the nondipping pattern of BP in a previous study included reverse dipping, which was recently regarded as an independent predictor for lacunar infarction and carotid plaque formation. ${ }^{78}$ No study has yet investigated any possible association between RDW and the reversedipper BP pattern.

In this study, we aimed to determine whether the level of RDW is elevated in patients with hypertension with the reverse-dipper BP pattern compared with other circadian BP patterns. In addition, we tried to evaluate the potential association of RDW levels with the decline rate of nocturnal BP in all patients with hypertension.

\section{METHODS}

\section{Study population}

We observed patients with essential hypertension continuously from January 2012 to June 2014. Data were extracted from our entire in-patient ABPM service database. Hypertension was diagnosed as $\mathrm{SBP} \geq 140 \mathrm{~mm} \mathrm{Hg}$ and/or diastolic BP (DBP) $\geq 90 \mathrm{~mm} \mathrm{Hg}$ in a casual office recording, or daytime (or awake) SBP $\geq$ $135 \mathrm{~mm} \mathrm{Hg}$ and/or DBP $\geq 85 \mathrm{~mm} \mathrm{Hg}$, or night-time (or asleep) $\mathrm{SBP} \geq 120 \mathrm{~mm} \mathrm{Hg}$ and/or $\mathrm{DBP} \geq 70 \mathrm{~mm} \mathrm{Hg}$ in ABPM. ${ }^{4}$ Diabetes mellitus (DM) was defined as fasting blood glucose $\geq 126 \mathrm{mg} / \mathrm{dL}$, casual blood glucose $\geq 200 \mathrm{mg} / \mathrm{dL}$ or $2 \mathrm{~h}$ blood glucose $\geq 200 \mathrm{mg} / \mathrm{dL}$ during a $75 \mathrm{~g}$ oral glucose tolerance test, or previous therapy for DM. ${ }^{20}$ Smoking status was ascertained on the basis of self-reported history of cigarette smoking. The exclusion criteria included age $<18$ or $>90$ years, incomplete clinical data, night workers, patients with diagnosis of secondary hypertension, under antihypertensive treatment, intolerance for the $24 \mathrm{~h} \mathrm{ABPM}$ and BP reading success rate $<70 \%$. Eventually, 708 patients with hypertension in total were included in our study. Physical examination and ABPM were performed for all patients. All patients were divided into three groups according to the presence of hypertension and circadian BP pattern as follows: dippers (average SBP decreased 10-20\% of daytime level during sleep), non-dippers $(<10 \%$ nocturnal SBP fall) and reverse dippers (SBP nocturnal rise) ${ }^{21}$

\section{ABPM assessment}

All patients with hypertension were evaluated with $24 \mathrm{~h}$ ABPM using an oscillometric device (Spacelabs 90207; Spacelabs, Redmond, Washington, USA). The monitor was installed on the non-dominant arm between 07:00 and 09:00 and removed $24 \mathrm{~h}$ later. Frequency of recordings was made at every $15 \mathrm{~min}$ from 07:00 to 23:00 (diurnal BP values) and every $30 \mathrm{~min}$ from 23:00 to 07:00 (nocturnal BP values). Strenuous physical activity was discouraged for all patients during the monitoring period. Recordings were accepted only if $>70 \%$ of the raw data were valid. ${ }^{4}$ All ABPM recordings were manually edited by two individual physicians unaware of the objective and risk factors. Values of SBP $<70$ or $>250 \mathrm{~mm} \mathrm{Hg}$, DBP $<40$ or $>150 \mathrm{~mm} \mathrm{Hg}$, and heart rate $<40$ or $>150 \mathrm{bpm}$ were excluded from the recording. Fewer than 3\% of the BP readings were rejected as artefacts on the basis of these criteria. The per cent change in nocturnal BP decline was calculated as follows: (mean diurnal BP-mean nocturnal BP)/mean diurnal BP×100.

\section{Biochemical measurements}

Baseline demographic, clinical and laboratory data were carefully recorded. Blood samples were collected from all patients in the morning after a fasting period of $12 \mathrm{~h}$. RDW was measured by automated haematology analysers according to the formula: RDW=(coefficient of variability of RBC/mean (mean corpuscular volume) ) $\times 100$.

\section{Statistical analysis}

All statistical analyses were performed using the SPSS software package V.18.0 (SPSS Inc, Chicago, Illinois, USA). Adequacy of all parameters to normal distribution was tested by using the Kolmogorov-Smirnov test. Parametric tests were applied to data with normal distribution, while non-parametric tests were applied to data without normal distribution. Descriptive statistics are presented as percentages for discrete variables and mean $\pm \mathrm{SD}$ for continuous normally distributed variables. Analysis of variance (ANOVA) test was used for statistical comparison of data that match with the normal distribution. Multinomial logistic regression was applied to explore the associations among relevant variables with ABPM results. Bivariate correlation analysis was employed to examine the association between RDW and the decline rate of nocturnal BP. A calculated difference of $p<0.05$ was considered to be statistically significant. 
All of the participants consented to participate after being informed of the nature and purpose of the study.

\section{RESULTS}

\section{Baseline characteristics of patients}

The clinical characteristics of patients in different groups according to circadian variations of $\mathrm{BP}$ were shown in table 1 . In our study, a total of 171 patients $(24.15 \%)$ had the reverse-dipper BP pattern. The nondipper pattern was observed in 370 patients with hypertension $(52.26 \%)$ and the dipper pattern in 167 patients $(23.59 \%)$. In addition, there were 10 extreme-dipper patients ( $>20 \%$ nocturnal SBP fall) who have been excluded from our study due to the insufficient sample size. Compared with the dipper group, patients of the reverse-dipper BP are older and more often suffering from DM, with a higher fasting blood glucose. There was significantly increased RDW in reverse dippers $(13.52 \pm 1.05)$ than in dippers $(13.25 \pm 0.85)$ of hypertension $(\mathrm{p}=0.012)$.

\section{Association of RDW with circadian BP patterns}

To explore the association of BP circadian patterns with $\mathrm{RDW}$, a multinomial logistic regression analysis using a stepwise selection process was performed in our study. Our univariate models included age, gender, smoking, diabetes, triglycerides, high-density lipoprotein cholesterol, low-density lipoprotein cholesterol (LDL-C), very low-density lipoprotein cholesterol, 24 h SBP, 24 h DBP, SBP awakening, SBP bedtime, DBP awakening, DBP bedtime and RDW. The variables with significance and accepted collinearity in univariate models were included in the multinomial analyses. It was discovered that RDW (OR $1.325,95 \%$ CI 1.037 to $1.692, \mathrm{p}=0.024$ ) and DM (OR 2.286, 95\% CI 1.380 to $3.788, \mathrm{p}=0.001$ ) were significantly different when comparing the reverse-dipper BP pattern with the dipper pattern (table 2). Additionally, RDW (OR 1.278, 95\% CI 1.027 to $1.591, \mathrm{p}=0.028$ ) and the LDL-C (OR $0.770,95 \%$ CI 0.625 to $0.947, \mathrm{p}=0.014$ ) were shown to be significantly different between nondipper and dipper (table 2). However, there was no significant difference of RDW between the non-dipper BP pattern and reverse-dipper BP pattern (OR 1.036, 95\% CI 0.867 to $1.238, \mathrm{p}=0.693$ ).

\section{Correlation between RDW level and decline rate of nocturnal BP}

$\mathrm{BP}$ nocturnal decline is a physiological response to a range of neuroendocrinological factors. The nocturnal decline rate is a continuous variable, which also shows the $\mathrm{BP}$ dipping status. The smaller the decline rate is, the more abnormal the dipping status will be. ${ }^{22}$ In order to further clarify the relationship between RDW level and the decline of nocturnal BP, bivariate correlation analysis was performed. Consistently, we found that RDW was negatively correlated with the decline rate of nocturnal SBP $(r=$ -0.113; $\mathrm{p}=0.003)$ and DBP $(\mathrm{r}=-0.101 ; \mathrm{p}=0.007)$ (figure 1 ).

Table 1 Characteristics of the study population by dipping status

\begin{tabular}{|c|c|c|c|c|}
\hline Variable & Dipper & Non-dipper & Reverse dipper & p Value \\
\hline Patients, $\mathrm{n}$ & 167 & 370 & 171 & \\
\hline Age, years & $56.99 \pm 14.01$ & $58.79 \pm 13.54$ & $64.92 \pm 11.97^{\star} \dagger$ & $<0.001$ \\
\hline Male/female, $\mathrm{n}$ & $93 / 74$ & $200 / 170$ & $90 / 81$ & 0.853 \\
\hline Current smokers, n (\%) & $37(22.16)$ & $118(31.89)$ & $55(32.16)$ & 0.052 \\
\hline Diabetes, n (\%) & 35 (20.96) & 95 (25.68) & $58(33.92)^{\star} \dagger$ & 0.023 \\
\hline Fasting glucose, $\mathrm{mmol} / \mathrm{L}$ & $5.12 \pm 1.90$ & $5.21 \pm 1.43$ & $5.85 \pm 3.02^{*} \dagger$ & 0.006 \\
\hline Triglycerides, mmol/L & $2.20 \pm 1.89$ & $1.82 \pm 1.25^{\star}$ & $1.63 \pm 1.20^{*}$ & 0.001 \\
\hline Total cholesterol, $\mathrm{mmol} / \mathrm{L}$ & $4.74 \pm 1.05$ & $4.58 \pm 0.93$ & $4.63 \pm 1.09$ & 0.235 \\
\hline $\mathrm{HDL}-\mathrm{C}, \mathrm{mmol} / \mathrm{L}$ & $1.23 \pm 0.31$ & $1.25 \pm 0.35$ & $1.27 \pm 0.34$ & 0.450 \\
\hline LDL-C, mmol/L & $2.86 \pm 1.06$ & $2.66 \pm 0.81^{*}$ & $2.72 \pm 0.88$ & 0.056 \\
\hline VLD-C, mmol/L & $0.70 \pm 0.57$ & $0.67 \pm 0.53$ & $0.65 \pm 0.58$ & 0.761 \\
\hline $24 \mathrm{~h}$ SBP, ABPM, mm Hg & $133.98 \pm 13.21$ & $135.44 \pm 13.79$ & $137.23 \pm 15.72^{*}$ & 0.106 \\
\hline SBP awakening, $\mathrm{mm} \mathrm{Hg}$ & $137.73 \pm 13.65$ & $136.97 \pm 13.94$ & $135.87 \pm 15.23$ & 0.478 \\
\hline SBP bedtime, mm Hg & $118.68 \pm 14.57$ & $129.78 \pm 13.75^{*}$ & $142.52 \pm 16.84^{*} \dagger$ & $<0.001$ \\
\hline Decline rate of nocturnal SBP, \% & $13.48 \pm 2.37$ & $5.16 \pm 2.82^{*}$ & $-5.09 \pm 4.39^{\star} \dagger$ & $<0.001$ \\
\hline 24 h DBP, ABPM, mm Hg & $78.99 \pm 11.79$ & $80.00 \pm 10.08$ & $79.11 \pm 10.04$ & 0.487 \\
\hline DBP awakening, $\mathrm{mm} \mathrm{Hg}$ & $82.01 \pm 10.68$ & $81.02 \pm 10.10$ & $78.86 \pm 9.98^{\star} \dagger$ & 0.014 \\
\hline DBP bedtime, $\mathrm{mm} \mathrm{Hg}$ & $69.49 \pm 10.17$ & $75.20 \pm 10.05^{\star}$ & $79.94 \pm 10.93^{*} \dagger$ & $<0.001$ \\
\hline Decline rate of nocturnal DBP, \% & $15.15 \pm 5.44$ & $7.22 \pm 5.36^{*}$ & $-1.51 \pm 6.58^{\star} \dagger$ & $<0.001$ \\
\hline RDW & $13.25 \pm 0.85$ & $13.46 \pm 1.03^{\star}$ & $13.52 \pm 1.05^{\star}$ & 0.026 \\
\hline
\end{tabular}

$\mathrm{p}$ Value for difference between the three groups.

*Indicated control with the dipper group $\mathrm{p}<0.05$.

tIndicated control with the non-dipper group $p<0.05$.

ABPM, ambulatory blood pressure monitoring; DBP, diastolic blood pressure; HDL-C, high-density lipoprotein cholesterol; LDL-C, low-density lipoprotein cholesterol; RDW, red blood cell distribution width; SBP, systolic blood pressure; VLD-C, very low-density lipoprotein cholesterol. 
Table 2 Multinomial logistic regression analysis among reverse dipper, non-dipper and dipper

\begin{tabular}{|c|c|c|c|c|c|c|c|}
\hline \multirow[b]{2}{*}{ Variable } & \multicolumn{2}{|c|}{ Reverse dipper vs dipper } & \multicolumn{2}{|l|}{ Non-dipper vs dipper } & \multicolumn{2}{|c|}{ Reverse dipper vs non-dipper } & \multirow[b]{2}{*}{$\begin{array}{l}\text { Global } \\
\mathbf{p}\end{array}$} \\
\hline & OR $(95 \% \mathrm{Cl})$ & $\begin{array}{l}\mathbf{p} \\
\text { Value }\end{array}$ & OR $(95 \% \mathrm{Cl})$ & $\begin{array}{l}\mathbf{p} \\
\text { Value }\end{array}$ & OR (95\% Cl) & $\begin{array}{l}\mathbf{p} \\
\text { Value }\end{array}$ & \\
\hline $\mathrm{D}$ & 2.286 (1.380 to 3.788$)$ & 0.001 & 9) & , & 9) & 28 & 005 \\
\hline Triglyceri & $0.713(0.585$ to 0.870$)$ & 0.001 & 0.850 (0.751 to 0.963$)$ & 0.011 & 7 to 1.011$)$ & 0.065 & 0.001 \\
\hline LDL-C & 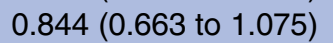 & & & & & & 0.047 \\
\hline RDW & 1.325 (1.037 to 1.692$)$ & 0.024 & 1.278 (1.027 to 1.591$)$ & 0.028 & $1.036(0.867$ to 1.238$)$ & 0.693 & 0.041 \\
\hline
\end{tabular}

Global $\mathrm{p}$ for significant difference between the three groups.

LDL-C, low-density lipoprotein cholesterol; RDW, red blood cell distribution width.

\section{DISCUSSION}

As far as we know, hypertension is a common chronic condition and important risk factor for heart attacks, stroke and other vascular and target organ damages. ${ }^{23}$ During the past 20 years, clinical investigations have demonstrated an important correlation between ABPM
Figure 1 Correlation of red blood cell distribution width (RDW) with the decline rate of nocturnal systolic blood pressure (SBP) and diastolic blood pressure (DBP).
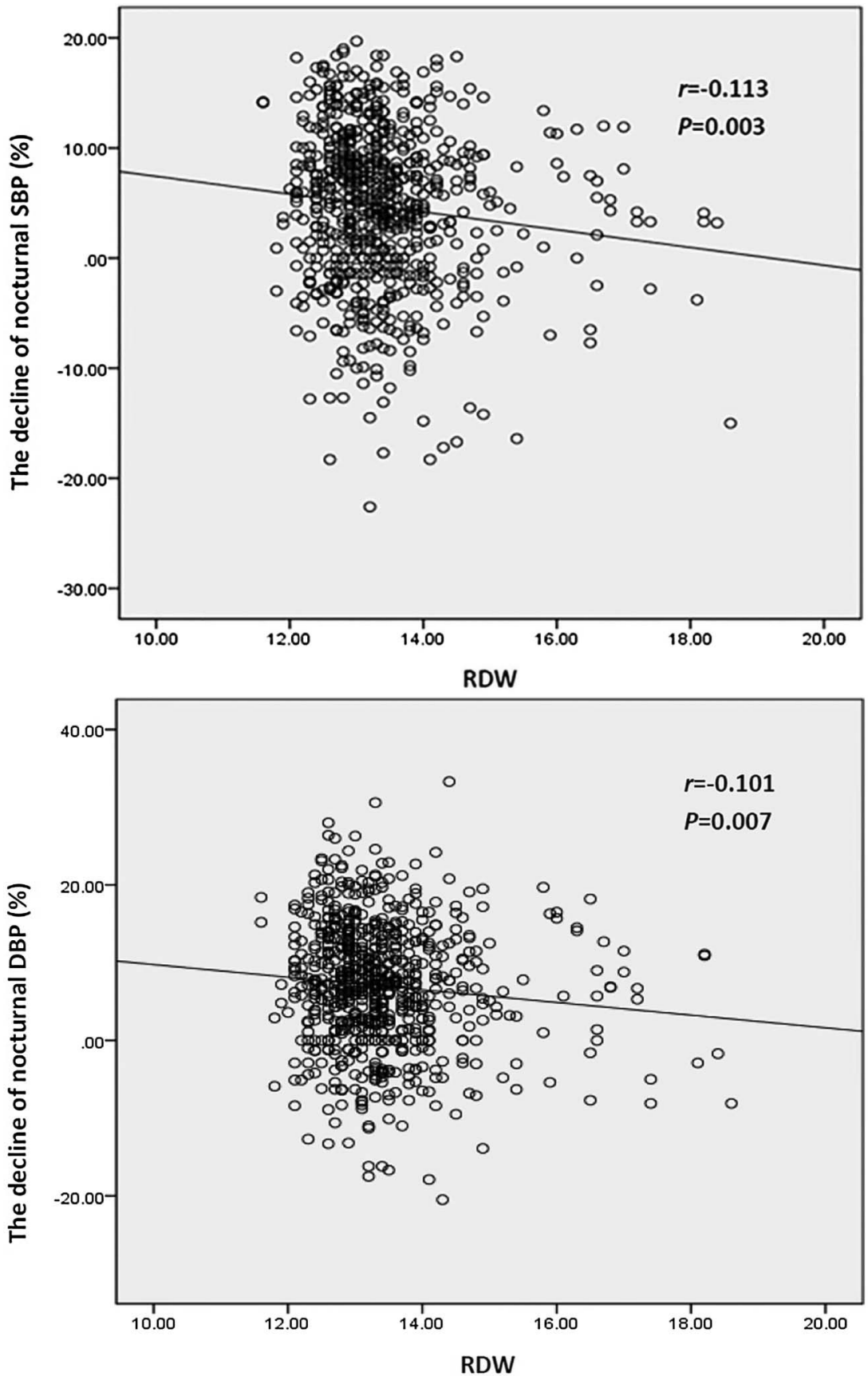
readings and prevalence and severity of cardiovascular events. ${ }^{24}$ In the first published study in central Italy, $\mathrm{ABPM}$ was found to be the best predictor of atherosclerotic events. ${ }^{26}$ Circadian $\mathrm{BP}$ variations were previously divided into dipper (mean nocturnal SBP drops $10 \mathrm{~mm} \mathrm{Hg}$ or more than that in daytime) and non-dipper (all other participants). ${ }^{21}{ }^{27}$ As a particular variant of the non-dipper pattern, the reverse-dipper pattern has a higher night-time SBP, compared with daytime values, which was reported to be associated with a higher incidence of cardiovascular events. ${ }^{28}$ Moreover, in our previous studies, only a reverse-dipper pattern of BP, instead of a non-dipper pattern, is crucial in the early development of carotid plaque and lacuna infarction. ${ }^{78}$

Previously, the correlation between RDW and hypertension, especially the non-dipper pattern of hypertension, has been demonstrated in many studies. ${ }^{29}$ Tanindi $e t a \ell^{30}$ found that RDW was significantly higher in patients with prehypertension and hypertension than in healthy subjects. ${ }^{31}$ Jithesh $e t a l^{31}$ also observed that both high-sensitive $\mathrm{C}$ reactive protein (hs-CRP) and RDW levels were higher in the hypertensive patient group compared with the control group. ${ }^{32}$ Furthermore, Wen ${ }^{29}$ showed that there was a close relationship between RDW levels and carotid artery atherosclerosis in patients with hypertension. Besides, researchers reported that increased RDW levels were associated with higher BP levels according to large community-based cohort studies. ${ }^{32}$ Moreover, studies investigating RDW in patients with hypertension also reported that RDW levels are significantly increased in patients with nondippers compared with those with dippers. ${ }^{18} 19$

RDW, a novel predictor of mortality, is strongly and independently associated with adverse outcomes in cardiovascular diseases. ${ }^{33}$ The possible mechanism of the relationship between RDW and cardiovascular diseases is proposed to be chronic inflammation. ${ }^{34}$ Lippi et al described the association between RDW and inflammatory markers such as the erythrocyte sedimentation rate and hs-CRP. ${ }^{35}$ RDW elevation might reflect an underlying chronic inflammation, which may be due to the increased risk of cardiovascular diseases. ${ }^{9}$ Additionally, oxidative stress was also revealed to play an important role in increased RDW in patients with cardiovascular diseases. ${ }^{36}$ However, the detailed mechanism remains to be further investigated.

In this study, we tried to determine whether any possible associations of circadian BP patterns, especially reverse dipping, with RDW levels existed in essential hypertension. We found that RDW levels were significantly higher in the reverse-dipper group than in the dipper group. In addition, we carried out multiple logistic regressions and indicated that RDW is strongly associated with reverse-dipper hypertension. Furthermore, we found that the decline rate in BP from day to night was negatively correlated with RDW levels. However, the difference in RDW level between non-dipper and reverse-dipper patterns was not observed. Accordingly, we concluded that RDW might associate with both nondipper and reverse-dipper hypertension.

\section{Limitations}

Several potential limitations should be noted. First, our study had a cross-sectional design, whereas a longer period of prospective observation may provide more prognostic information. Second, the participants in our study are exclusively limited to northern Chinese patients from a single centre; therefore, the conclusions should be drawn cautiously for other ethnic groups. Third, we excluded 10 extreme dippers from the analysis in this study for their small sample size. Therefore, extreme dipping could be investigated in the future provided enough patients are recruited. Finally, although we demonstrated a possible association between elevated RDW and BP abnormal dipper patterns, their clinical significance requires further prospective investigation.

\section{CONCLUSION}

In conclusion, our study provides evidence that RDW may independently associate with the abnormal dipper patterns of BP.

\section{Author affiliations}

${ }^{1}$ Department of Cardiology, The Second Affiliated Hospital, Xi'an Jiaotong University, Xi'an, China

${ }^{2}$ Department of Emergency Medicine, The Second Affiliated Hospital, Xi'an Jiaotong University, Xi'an, China

${ }^{3}$ Department of Nephrology, The Second Affiliated Hospital, Xi'an Jiaotong University, Xi'an, China

${ }^{4}$ Department of Hematology, The Second Affiliated Hospital, Xi'an Jiaotong University, Xi'an, China

Contributors GW, DS, JH, AS and FZ contributed to the design of the work. DS and JH collected the data. DS and QG wrote the manuscript. QG, YG, BY and LP were involved in the analysis and interpretation of data. GW, BY, AS and FZ reviewed the manuscript.

Funding This work was supported by the Natural Sciences Foundation of China (81300116) and the Ministry of Education of China (the Research Fund for Young Scholars of Higher Education Doctoral Program in China, 20120201120083 and the Fundamental Research Funds for the Central Universities, XJJ2013062) and the Ministry of Science and Technology of Shaanxi Province (2015KJXX-06).

Competing interests None declared.

Patient consent Obtained.

Ethics approval The study was approved by the ethics committee of the Second Affiliated Hospital, Xi'an Jiaotong University.

Provenance and peer review Not commissioned; externally peer reviewed.

Data sharing statement No data are available.

Open Access This is an Open Access article distributed in accordance with the Creative Commons Attribution Non Commercial (CC BY-NC 4.0) license, which permits others to distribute, remix, adapt, build upon this work noncommercially, and license their derivative works on different terms, provided the original work is properly cited and the use is non-commercial. See: http:// creativecommons.org/licenses/by-nc/4.0/

\section{REFERENCES}

1. Lewington S, Clarke R, Qizilbash N, et al. Age-specific relevance of usual blood pressure to vascular mortality: a meta-analysis of 
individual data for one million adults in 61 prospective studies. Lancet (London, England) 2002;360:1903-13.

2. Turner JR, Viera AJ, Shimbo D. Ambulatory blood pressure monitoring in clinical practice: a review. Am J Med 2015;128:14-20.

3. Bliziotis IA, Destounis A, Stergiou GS. Home versus ambulatory and office blood pressure in predicting target organ damage in hypertension: a systematic review and meta-analysis. J Hypertens 2012;30:1289-99.

4. Mancia G, Fagard R, Narkiewicz K. 2013 ESH/ESC Guidelines for the management of arterial hypertension: the Task Force for the management of arterial hypertension of the European Society of Hypertension $(\mathrm{ESH})$ and of the European Society of Cardiology (ESC). J Hypertens 2013;31:1281-357.

5. Kaya MG, Yarlioglues M, Gunebakmaz O, et al. Platelet activation and inflammatory response in patients with non-dipper hypertension. Atherosclerosis 2010;209:278-82.

6. Kario K, Pickering TG, Matsuo T, et al. Stroke prognosis and abnormal nocturnal blood pressure falls in older hypertensives. Hypertension 2001;38:852-7.

7. Yan B, Peng L, Han D, et al. Blood pressure reverse-dipping is associated with early formation of carotid plaque in senior hypertensive patients. Medicine (Baltimore) 2015;94:e604.

8. Yan B, Peng L, Dong Q, et al. Reverse-dipper pattern of blood pressure may predict lacunar infarction in patients with essential hypertension. Eur J Neurol 2015;22:1022-5.

9. Felker GM, Allen LA, Pocock SJ, et al. Red cell distribution width as a novel prognostic marker in heart failure: data from the charm program and the duke databank. J Am Coll Cardiol 2007;50:40-7.

10. Tonelli M, Sacks F, Arnold M, et al. Relation between red blood cell distribution width and cardiovascular event rate in people with coronary disease. Circulation 2008;117:163-8.

11. Karnad A, Poskitt TR. The automated complete blood cell count Use of the red blood cell volume distribution width and mean platelet volume in evaluating anemia and thrombocytopenia. Arch Intern Med 1985;145:1270-2.

12. Salvagno GL, Sanchis-Gomar F, Picanza A, et al. Red blood cell distribution width: a simple parameter with multiple clinical applications. Crit Rev Clin Lab Sci 2015;52:86-105.

13. Dogan M, Kucuk U, Uz O. Red blood cell distribution width is worthwhile when interpreted with other inflammatory markers. J Geriatr Cardiol 2015;12:457-8.

14. Hampole CV, Mehrotra AK, Thenappan T, et al. Usefulness of red cell distribution width as a prognostic marker in pulmonary hypertension. Am J Cardiol 2009;104:868-72.

15. Allen LA, Felker GM, Mehra MR, et al. Validation and potential mechanisms of red cell distribution width as a prognostic marker in heart failure. J Card Fail 2010;16:230-8.

16. Malandrino N, Wu WC, Taveira TH, et al. Association between red blood cell distribution width and macrovascular and microvascular complications in diabetes. Diabetologia 2012;55:226-35.

17. Ani C, Ovbiagele B. Elevated red blood cell distribution width predicts mortality in persons with known stroke. J Neurol SCi 2009;277:103-8.

18. Ozcan F, Turak O, Durak A, et al. Red cell distribution width and inflammation in patients with non-dipper hypertension. Blood Press 2013;22:80-5.
19. Gunebakmaz O, Kaya MG, Duran M, et al. Red blood cell distribution width in 'non-dippers' versus 'dippers'. Cardiology 2012;123:154-9.

20. Zargar AH, Wani AA, Laway BA, et al. Prevalence of diabetes mellitus and other abnormalities of glucose tolerance in young adults aged 20-40 years in North India (Kashmir Valley). Diabetes Res Clin Pract 2008;82:276-81.

21. O'Brien E, Sheridan J, O'Malley K. Dippers and non-dippers. Lancet 1988;2:397.

22. Inanc T, Kaya MG, Yarlioglues M, et al. The mean platelet volume in patients with non-dipper hypertension compared to dippers and normotensives. Blood Press 2010;19:81-5.

23. Kannel WB. Blood pressure as a cardiovascular risk factor: prevention and treatment. JAMA 1996;275:1571-6.

24. Fagard RH, Celis $\mathrm{H}$, Thijs L, et al. Daytime and nighttime blood pressure as predictors of death and cause-specific cardiovascular events in hypertension. Hypertension 2008;51:55-61.

25. Schillaci G, Parati G. Determinants of blood pressure variability in youth: at the roots of hypertension. $J$ Hypertens 2010;28:660-4.

26. Verdecchia P, Schillaci G, Reboldi G, et al. Different prognostic impact of 24-hour mean blood pressure and pulse pressure on stroke and coronary artery disease in essential hypertension. Circulation 2001;103:2579-84.

27. McAlister FA, Straus SE. Evidence based treatment of hypertension. Measurement of blood pressure: an evidence based review. BMJ 2001:322:908-11.

28. Bouhanick B, Bongard V, Amar J, et al. Prognostic value of nocturnal blood pressure and reverse-dipping status on the occurrence of cardiovascular events in hypertensive diabetic patients. Diabetes Metab 2008;34:560-7.

29. Wen Y. High red blood cell distribution width is closely associated with risk of carotid artery atherosclerosis in patients with hypertension. Exp Clin Cardiol 2010;15:37-40.

30. Tanindi A, Topal FE, Topal F, et al. Red cell distribution width in patients with prehypertension and hypertension. Blood Press 2012;21:177-81.

31. Jithesh TK, Jayapal V, Vijayakumar T, et al. Red cell distribution width and high sensitivity C-reactive protein as risk markers in hypertension. Int J Med Sci Public Health 2012:1:138-42.

32. Perlstein TS, Weuve J, Pfeffer MA, et al. Red blood cell distribution width and mortality risk in a community-based prospective cohort. Arch Intern Med 2009;169:588-94.

33. Ye Z, Smith C, Kullo IJ. Usefulness of red cell distribution width to predict mortality in patients with peripheral artery disease. Am J Cardiol 2011;107:1241-5.

34. Lappé JM, Horne BD, Shah SH, et al. Red cell distribution width, C-reactive protein, the complete blood count, and mortality in patients with coronary disease and a normal comparison population. Clin Chim Acta 2011;412:2094-9.

35. Lippi G, Targher G, Montagnana M, et al. Relation between red blood cell distribution width and inflammatory biomarkers in a large cohort of unselected outpatients. Arch Pathol Lab Med 2009;133:628-32.

36. Weiss G, Goodnough LT. Anemia of chronic disease. N Engl J Med 2005;352:1011-23. 